\title{
Metallonics
}

www.rsc.org/metallomics

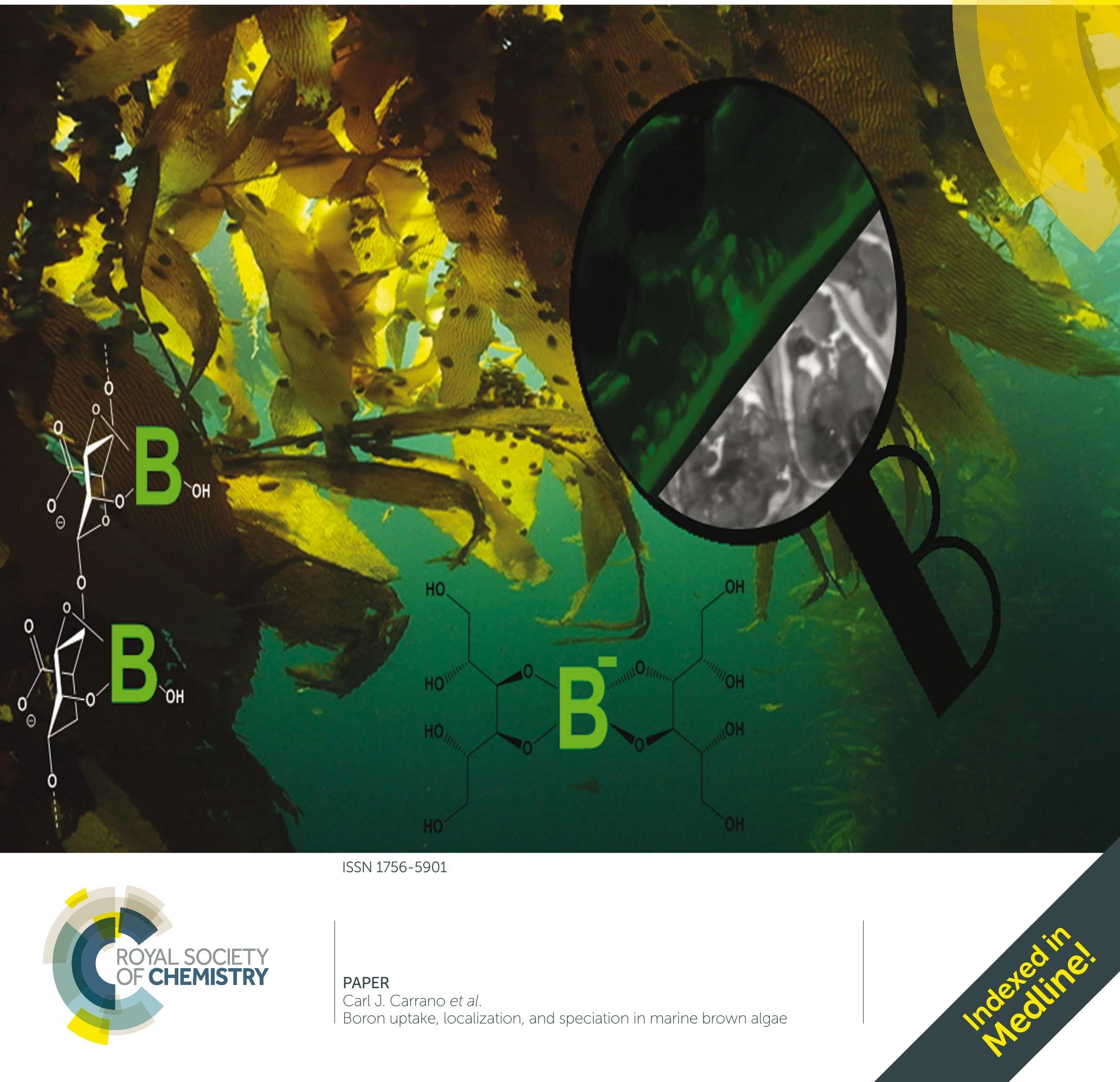




\title{
Metallomics
}

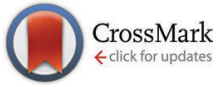

Cite this: Metallomics, 2016, 8,161

Received 11th September 2015, Accepted 2nd December 2015

DOI: 10.1039/c5mt00238a

www.rsc.org/metallomics

\section{Boron uptake, localization, and speciation in marine brown algae $\dagger$}

\begin{abstract}
Eric P. Miller, ${ }^{a}$ Youxian $\mathrm{Wu}^{\mathrm{b}}$ and Carl J. Carrano*a
In contrast to the generally boron-poor terrestrial environment, the concentration of boron in the marine environment is relatively high $(0.4 \mathrm{mM})$ and while there has been extensive interest in its use as a surrogate of $\mathrm{pH}$ in paleoclimate studies in the context of climate change-related questions, the relatively depth independent, and the generally non-nutrient-like concentration profile of this element have led to boron being neglected as a potentially biologically relevant element in the ocean. Among the marine plant-like organisms the brown algae (Phaeophyta) are one of only five lineages of photosynthetic eukaryotes to have evolved complex multicellularity. Many of unusual and often unique features of brown algae are attributable to this singular evolutionary history. These adaptations are a reflection of the marine coastal environment which brown algae dominate in terms of biomass. Consequently, brown algae are of fundamental importance to oceanic ecology, geochemistry, and coastal industry. Our results indicate that boron is taken up by a facilitated diffusion mechanism against a considerable concentration gradient. Furthermore, in both Ectocarpus and Macrocystis some boron is most likely bound to cell wall constituent alginate and the photoassimilate mannitol located in sieve cells. Herein, we describe boron uptake, speciation, localization and possible biological function in two species of brown algae, Macrocystis pyrifera and Ectocarpus siliculosus.
\end{abstract}

\section{Introduction}

Boron has been known to be an essential micronutrient for all terrestrial plants and many other organisms since at least the 1920s. However, it can also be toxic at higher environmental concentrations suggesting a rather narrow optimal concentration window. ${ }^{1,2}$ A considerable amount of literature has focused on the element from the perspective of its effects on terrestrial agriculture where there are examples of both boron deficiency and toxicity. ${ }^{1,3,4}$ As a consequence, both boron-tolerant and boron-efficient cultivars have been developed. The essentiality of boron to higher plants stems from its ability to crosslink cell wall carbohydrates. The first isolated B-cell wall complex was identified as the bis-diester of boron with the pectic polysaccharide rhamnogalacturonan II (RG-II). ${ }^{5}$ Monomeric RG-II has four side chains, two of which contain apiose. The apiosyl residues engage in spirocyclic borate-crosslinking between apiofuranosyl residues of two 2-O-methyl-D-xylose sidechains resulting in a dimeric complex. In general, borate reacts most strongly with

\footnotetext{
${ }^{a}$ Department of Chemistry and Biochemistry,

San Diego State University, San Diego, CA 92182-1030, USA.

E-mail: ccarrano@mail.sdsu.edu; Tel: +1 6195941617

${ }^{b}$ Department of Civil, Construction, and Environmental Engineering,

San Diego State University, San Diego, CA 92182-1030, USA

$\dagger$ Electronic supplementary information (ESI) available. See DOI: 10.1039/c5mt00238a
}

sugars that have cis-1,2-diols on a furanoid ring as a result of both steric and electronic forces. ${ }^{6,7}$

In contrast to the generally boron-poor terrestrial environment, the concentration of boron in the marine environment is relatively high $(0.4 \mathrm{mM})$ and while there has been extensive interest in its use as a surrogate of $\mathrm{pH}$ in paleoclimate studies in the context of climate change-related questions, the relatively depth independent, and the generally non-nutrient-like concentration profile of this element have led to it being neglected as potentially biologically relevant. ${ }^{8}$ This dearth of research persists despite the fact that a number of studies report that boron is essential for the growth and development in many marine plant-like linkages and that it is recognized as an important constituent of algal culture media. ${ }^{9}$ For example, in the marine red algae Bangia and Porphyra, boron at seawater concentrations is essential for sustained growth, while Lewin demonstrated the requirement of boron for the growth of marine pennate and centric diatoms. ${ }^{10-14}$ An essential role of boron in the development of the brown macroalgae Fucus edentatus (Phaeophyceae) was also recognized whereby omission of boron from the culture medium resulted in moribund embryos with normal development being restored by adding 1-4 $\mu \mathrm{M}$ boron. ${ }^{15}$ Gametogenesis in brown algal gametophytes (of the kelps Laminaria japonica and L. angustata and of the sulfuric acid-producing Desmarestia ligulata) is also known to be strongly affected by the availability of boron. ${ }^{16}$ Demonstration of the presence of boroesters in marine plants 
was initially described for a sulfated polysaccharide of the green seaweed Ulva lactuca and later shown by ${ }^{11} \mathrm{~B}$ NMR to also be present in red and brown macroalgae. ${ }^{17,18}$

Among the marine plant-like organisms, the brown algae (Phaeophyta) are one of only three lineages of photosynthetic eukaryotes to have evolved complex multicellularity. Many of the unusual and often unique features of brown algae are attributable to this singular evolutionary history. These adaptations are a reflection of the marine coastal environment which brown algae dominate in terms of biomass. For example, extensive kelp forests effectively serve as an interface between the ocean, atmosphere and land masses, whereas some filamentous seaweeds (e.g. Ectocarpus sp.) accumulate on man-made surfaces as fouling organisms to such extents that they are a nuisance in marine industries. Consequently, brown algae are of fundamental importance to oceanic ecology, geochemistry, and coastal industry. Just as brown algae morphology differ greatly by order, their ecological roles and industrial applications differ as well.

Herein, we describe boron uptake, speciation, localization and possible biological function in two species of brown algae: Macrocystis pyrifera and Ectocarpus siliculosus. With a length of up to $60 \mathrm{~m}$, Macrocystis is by far the largest seaweed in the world and, indeed, one of the largest organisms on Earth. Macrocystis is also the single largest source of raw material for the global alginate industry and supports an economic activity of several hundred million dollars annually. ${ }^{19}$ Ectocarpus is one of the best-studied seaweeds and has many significant advantages as an experimental model. In addition to being easily cultured in the laboratory, it is the first seaweed of which the entire genome has been sequenced and thus offers many opportunities for study.

\section{Materials and methods}

\section{Biological material}

E. siliculosus CCAP 1310/56 was obtained from the Culture Collection of Algae and Protozoa (CCAP) at the Scottish Association for Marine Science and grown axenically in modified Provasolienriched (Andersen, 2005) Scripps Pier seawater (SPSW) at $15{ }^{\circ} \mathrm{C}$ under a 12/12 light/dark photocycle. ${ }^{20} \mathrm{M}$. pyrifera was harvested from the Point Loma kelp forest $(32.7 \mathrm{~N}, 117.3 \mathrm{~W})$ and either used immediately after collection or maintained in modified Provasoli-enriched Scripps Pier seawater (SPSW) at $12{ }^{\circ} \mathrm{C}$ under a 12/12 light/dark photocycle.

\section{Histochemistry}

Algal tissue was cryo-fixed in liquid nitrogen and sectioned with a Leica CM1950 cryostat (Leica Microsystems, Inc., USA). Sections (50 $\mu \mathrm{m}$ thickness) were placed on glass well slides and allowed to thaw. Once thawed, sections were incubated for 2 min with 3-(3-(3',6'-dihydroxy-3-oxo-3H-spiro[isobenzofuran1,9'-xanthene]-5-yl)thioureido)phenylboronic acid (B-FITC) prepared as described by Glüsenkamp et al., $1997 .{ }^{21}$ Sections were washed thoroughly with $\mathrm{pH} 8$ phosphate buffer before fluorescence imaging with a Nikon Eclipse TE2000-U inverted microscope (Nikon Imaging, Inc., Japan).

\section{Energy-dispersive X-ray spectroscopy (EDS)}

Cells were fixed in a $0.1 \mathrm{M}$ phosphate buffer solution containing $2 \%(\mathrm{w} / \mathrm{v})$ paraformaldehyde and $1 \%(\mathrm{w} / \mathrm{v})$ glutaraldehyde for $2 \mathrm{~h}$. Fixed cells were then washed with $0.1 \mathrm{M}$ phosphate buffer and dehydrated in successive ethanol baths of 30, 50, 75, 85, 95, and $100 \%(\times 3)$. The cells were then infiltrated with $1: 1(\mathrm{v} / \mathrm{v})$ ethanol/ LR White embedding medium (Electron Microscopy Sciences, USA) for $3 \mathrm{~h}$ followed by $100 \%$ LR White overnight. Cells were embedded in $100 \%$ LR White at $60{ }^{\circ} \mathrm{C}$ under vacuum for $6 \mathrm{~h}$. Sections (60 nm thickness) were cut on a Reichert-Jung Ultracut E microtome (Reichert, Austria) and floated onto formvar-coated 100-mesh copper grids (Ted Pella, USA). Grids were placed in a sample holder on a stage which facilitates deployment of a transmitted electron detector in the scanning electron microscope (SEM) chamber. Samples were analyzed under high vacuum in a Quanta 450 FEG SEM equipped with an INCA (Oxford Instruments, USA) energy-dispersive X-ray microanalysis system. Uncoated samples allowed simultaneous transmitted electron imaging and X-ray analysis with low accelerating voltage (5-7 keV).

\section{Nuclear magnetic resonance}

All NMR experiments were carried out on a Varian $500 \mathrm{MHz}$ NMR spectrometer (Varian Inc., USA) using fresh algal material cored with a $3 \mathrm{~mm}$ diameter tool and immediately inserted into NMR tubes and placed in the spectrometer maintained at $5{ }^{\circ} \mathrm{C}$. 10000 scans were acquired with standard pulse sequences (50 ms pulse duration, $50 \mathrm{~ms}$ relaxation) for the ${ }^{11} \mathrm{~B}$ experiments. To eliminate the broad borosilicate background of glass NMR tubes, quartz NMR tubes (Wilmad-Labglass, USA) were used throughout. The remaining borosilicate background from the instrument probe was manually subtracted using the NMR data processing software MestRe-C (MestreLab Research, Spain). Samples were referenced relative to an external standard of $\mathrm{BF}_{3}$-etherate.

\section{Raman microscopy}

Cryosections of $50 \mu \mathrm{m}$ thickness were placed on crystalline silicon wafers and lyophilized. Dry sections were imaged with a Thermo Scientific DXR Raman microscope (Thermo Fisher Scientific, USA) and then scanned at $2 \mu \mathrm{m}$ resolution with a $532 \mathrm{~nm}$ laser at $10 \mathrm{~mW}$ power. Each spectrum was backgroundsubtracted and relevant peaks were selected for creating maps of a specific Raman shift.

\section{Inductively-coupled plasma mass spectrometry}

E. siliculosus filaments and M. pyrifera fronds were grown under boron-limited conditions for 48 hours followed by incubation with $0.4 \mathrm{mM}$ borate enriched artificial seawater (ASW). Fresh algal tissue samples were washed with borate-free artificial seawater and weighed. Samples were placed in a digestion solution containing $3.5 \%$ tetramethylammonium hydroxide (Sigma) and heated to $90{ }^{\circ} \mathrm{C}$ for $3 \mathrm{~h}$. Remaining contents were then brought to $7 \mathrm{~mL}$ with nanopure water and filtered through $0.2 \mu \mathrm{m}$ Isopore $^{\mathrm{TM}}$ membrane filters (Millipore, USA). 
The analysis for boron was performed by inductively coupled plasma mass spectroscopy (Agilent 7500cx, Agilent Technologies, Inc., USA). The instrument was operated using Spectrum Multi Tune under the following operational conditions: plasma forward power: $1.55 \mathrm{~kW}$, RF matching $1.78 \mathrm{~V}$, carrier gas (Ar) $0.86 \mathrm{~L} \mathrm{~min}^{-1}$ and makeup gas (Ar) $0.20 \mathrm{~L} \mathrm{~min}^{-1}$. MicroMist nebulizer was used and the nebulizer pump rate was at 0.1 rps. Agilent ICP-MS ChemStation was used to control operation and record data. All the determinations were performed in triplicate using the external standard calibration method and with ${ }^{9} \mathrm{Be}$ as the internal standard for ${ }^{10} \mathrm{~B}$. All calibration standards were prepared in $0.5 \%$ TMAH. Quality assurance/quality control procedures included blanks, spikes, and standard reference materials, and all results were within acceptable limits. To obtain analyte concentration in the solution, calibration with standard solution concentrations of 1, 2, 10, 25, 50, 100, 200, 500, 1000 and $5000 \mu \mathrm{g} \mathrm{L^{-1 }}$ were prepared from certified reference material (High-Purity Standards, USA). The standard calibration was carried out every single analysis. The ICP-MS method and smart sequences of sample analysis were optimized to eliminate boron memory effects.

\section{Results}

\section{Boron uptake}

Boron uptake by E. siliculosus and $M$. pyrifera was quantified by ICP-MS elemental analysis of algal biomass over a 24 hour period (see Materials and methods). Ectocarpus exhibits near linear uptake for $\sim 4 \mathrm{~h}$, after which uptake ceased (Fig. 1). Concentration-dependent boron uptake data during the linear uptake period (Fig. 2) most accurately fits a biphasic system consisting of both a saturable carrier-assisted transport and a non-saturable diffusion-limited transport as defined by Neame and Richards (Neame and Richards, 1972): ${ }^{22}$

$$
\text { Rate }=\frac{V_{\max } \cdot[\mathrm{S}]}{K_{\mathrm{M}}+[\mathrm{S}]}+K_{\mathrm{D}} \cdot[\mathrm{S}]
$$

where $V_{\max }$ is the maximum carrier transport rate, [S] is the substrate concentration, $K_{\mathrm{M}}$ is the Michaelis constant, and $K_{\mathrm{D}}$ is

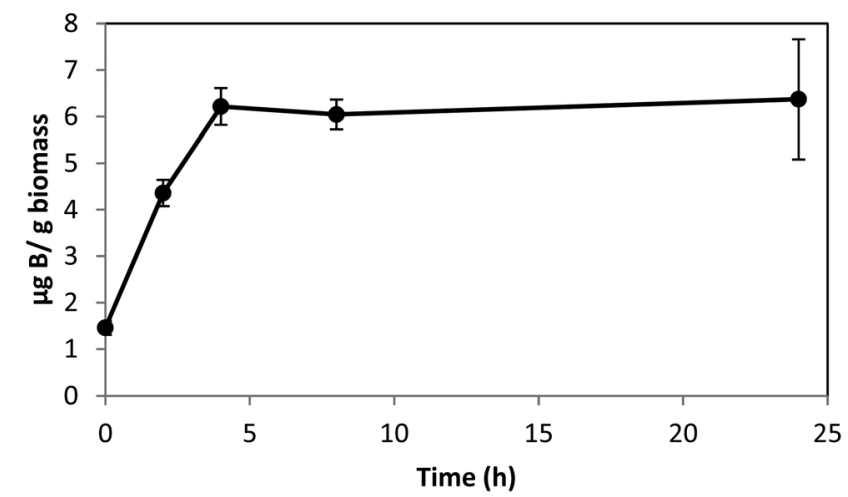

Fig. 1 Boron uptake in Ectocarpus from ASW medium enriched with $0.4 \mathrm{mM}$ borate as a function of time. Error bars represent \pm 1 S.D. from duplicate experiments with replicate time points for each.

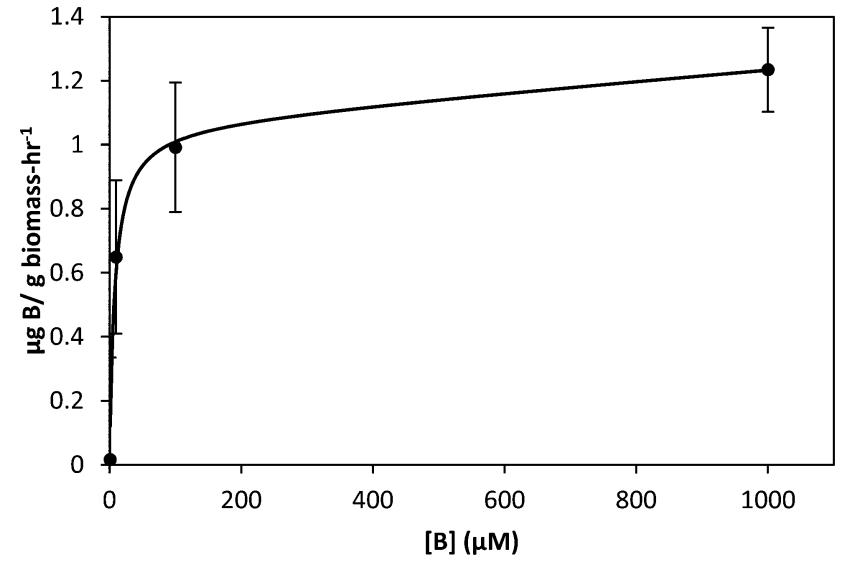

Fig. 2 Uptake of boron by Ectocarpus after two hour incubation in ASW medium as a function of boron concentration. Data points are shown as circles while the solid line represents fits to the data as described in the text. Error bars represent \pm 1 S.D. from duplicate experiments with replicate concentration points for each.

the diffusion constant. Non-linear least squares fits to the data implemented using Sigma Plot $12.5^{\mathrm{TM}}$ (Systat Software Inc., USA) yielded $V_{\max }=1.07 \mathrm{ng}$ B mg biomass ${ }^{-1} \mathrm{~h}^{-1}, K_{\mathrm{m}}=7.8 \mu \mathrm{M}$, and $K_{\mathrm{D}}=1.7 \times 10^{-4} \mathrm{ng} \mathrm{B} \mathrm{mg} \mathrm{biomass}{ }^{-1} \mathrm{~h}^{-1} \mu \mathrm{M}^{-1}$.

Macrocystis blade and stipe take up significantly more boron than seen with Ectocarpus (Fig. 3). We examined uptake by both blade and stipe. Blade uptake slows over a 24 hour period while near linear boron uptake in the stipe continues over the same period. In contrast to Ectocarpus, a diffusion parameter is not necessary to fit concentration dependent boron uptake in Macrocystis (see Fig. S1, ESI $\dagger$ ). Blade and stipe both display low affinity saturation kinetics with $V_{\max }=150 \mathrm{ng} \mathrm{B} \mathrm{mg} \mathrm{biomass}{ }^{-1} \mathrm{~h}^{-1}$, $K_{\mathrm{m}}=863 \mu \mathrm{M}$ and $V_{\max }=30 \mathrm{ng}$ B mg biomass $^{-1} \mathrm{~h}^{-1}, K_{\mathrm{m}}=318 \mu \mathrm{M}$, respectively.

\section{Boron localization}

The localization of boron in brown algal tissue was investigated using two separate means. The first involves determining the location of likely boron binding sites (cis-diols), the two most

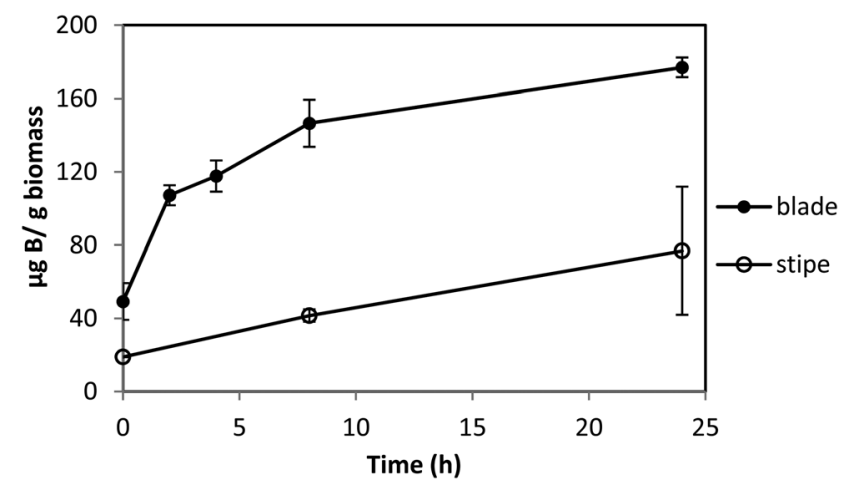

Fig. 3 Boron uptake by Macrocystis blade (upper) and stipe (lower) from ASW medium enriched with $0.4 \mathrm{mM}$ borate as a function of time. Error bars represent \pm 1 S.D. from duplicate experiments with replicate time points for each. 
likely of which are the primary carbon storage molecule mannitol, and the primary structural carbohydrate, alginic acid. We used micro Raman spectroscopy to identify high concentrations of these species and compared their localization with that found for the fluorescent dye phenylboronic acid-fluorescein isothiocyanate (B-FITC) which has previously been used as a probe for boron binding sites in terrestrial plants (Glüsenkamp et al., 1997). B-FITC likely forms highly fluorescent monoesters with cis-diol species since the stable $\mathrm{B}-\mathrm{C}$ bond in phenylboronic acid precludes formation of borodiesters. ${ }^{21}$

Treatment of Ectocarpus with B-FITC leads to a fluorescence signal that is diffuse in some areas while discrete in other structured areas such as the plastids visible in the bright-field image of Fig. 4A and B. Although some of the fluorescence appears to be intracellular, a strong signal is seen in the apoplast as well (Fig. 4C and D). Macrocystis exhibits much more cellular and tissue differentiation with many different potential ligand environments as compared to Ectocarpus and correspondingly leads to a more complex staining pattern. B-FITC signal is localized to the meristoderm, cortical, and medullar apoplasts in the blade and stipe (Fig. 5 and Fig. S2, ESI $\dagger$ ). In the stipe cortex, fluorescence from secretory cells (black arrows) suggests significant amounts of cis-diols (Fig. 5F). Sieve cells in the stipe medulla also fluoresce, indicating a possible transported metabolite with cis-diol groups (Fig. 5D).

With the apparent strong fluorescent signal of the B-FITC probe in the apoplast and sieve cells of Macrocystis suggesting high concentrations of potential boron binding ligands, we used micro-Raman spectroscopy to identify likely candidates. Fig. 6 shows a complete Raman spectrum of the apoplastic region of a Macrocystis cortical cell along with a heat map of Raman spectral intensity at $955 \mathrm{~cm}^{-1}$. The Raman spectrum displayed has been identified as that of alginate by comparison with the literature. ${ }^{23}$ As can be seen, the intensity of the $955 \mathrm{~cm}^{-1}$ band indicative of the presence of alginate, is concentrated in the apoplastic regions of the cortical cells. This mirrors the staining pattern seen for the same cell type with the B-FITC probe suggesting boron binding to alginate in the apoplast of these cells.
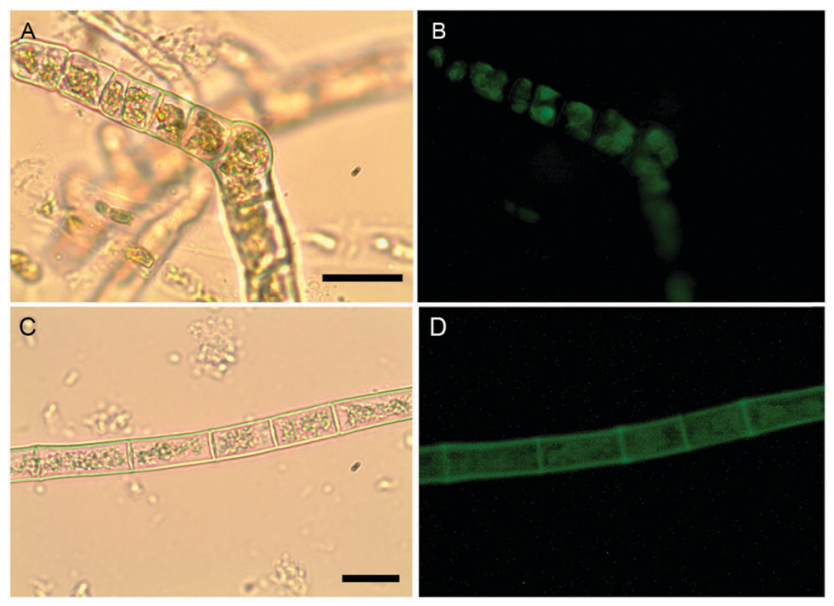

Fig. 4 Ectocarpus. (A and C) Brightfield transmission, (B and D) B-FITC fluorescence. Scalebars, $30 \mu \mathrm{m}$.
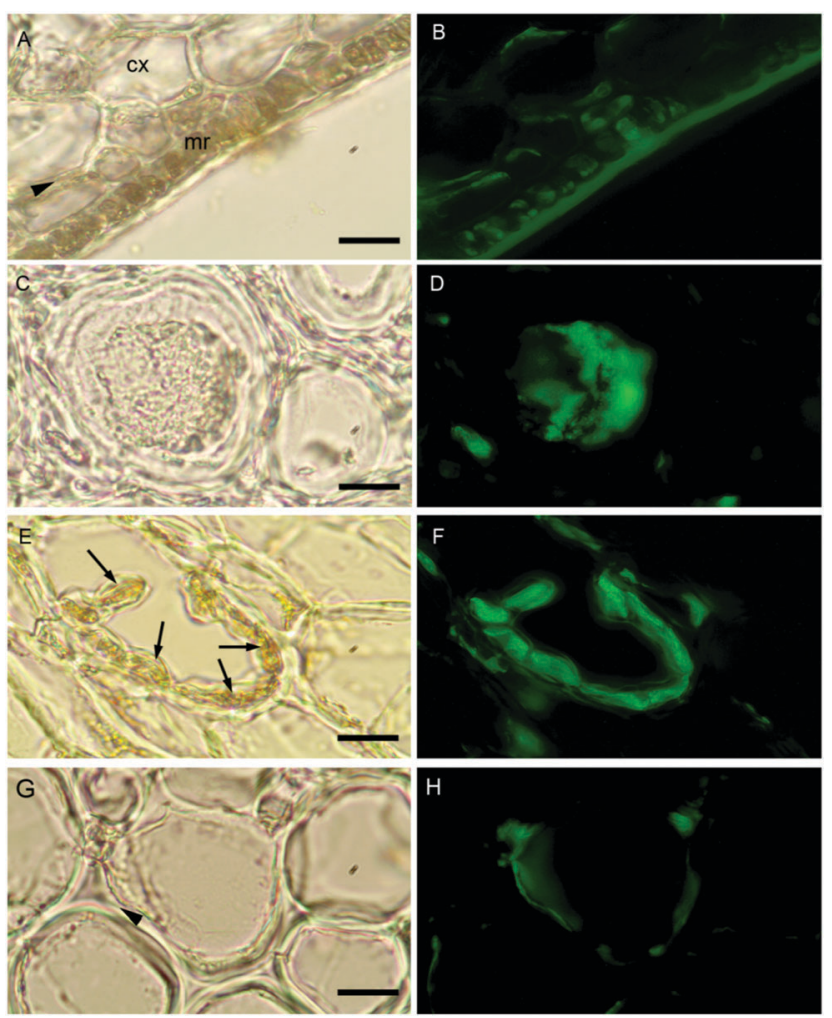

Fig. 5 Macrocystis stipe. Meristoderm (A) Brightfield transmission and (B) B-FITC fluorescence. (C and D) Medullar sieve cells. ( $E$ and F) Cortex with secretory cells (arrows). (G and H) Cortex cells. Meristoderm (mr), cortex (cx), arrowheads indicate apoplasts. Scalebars, $20 \mu \mathrm{m}$.

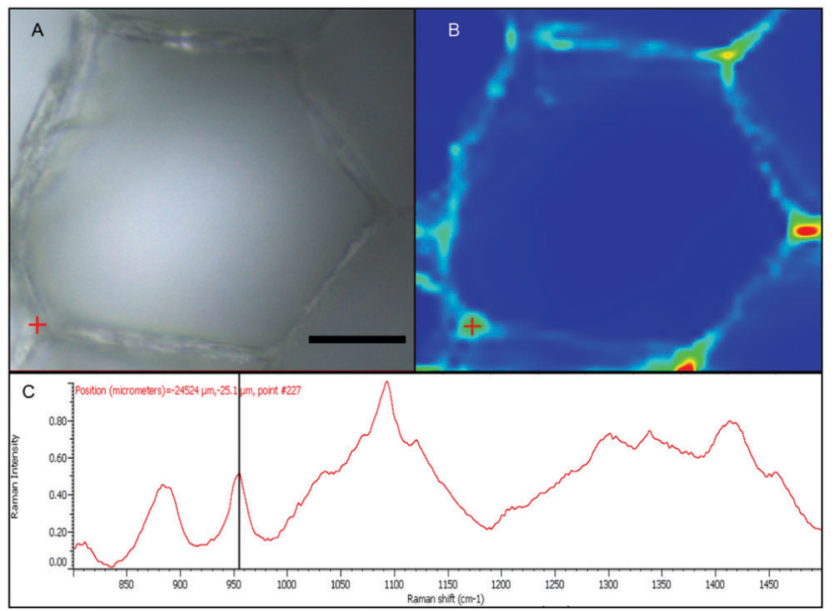

Fig. 6 Macrocystis cortex. (A) Brightfield. (B) Heatmap of the $955 \mathrm{~cm}^{-1}$ Raman shift. (C) Raman spectrum of the point indicated by the red crosshairs in (A) and (B). Scalebar, $20 \mu \mathrm{m}$.

In comparison, different results were seen when sieve cells were examined. Here, the Raman spectrum (Fig. 7C) appears to be that of mannitol as determined by comparison with a pure standard (Fig. 7D). A corresponding heat map based on the $875 \mathrm{~cm}^{-1}$ Raman shift characteristic of mannitol shows a concentration of this species in the sieve cells. Again this mirrors the staining pattern of B-FITC for these cells. 


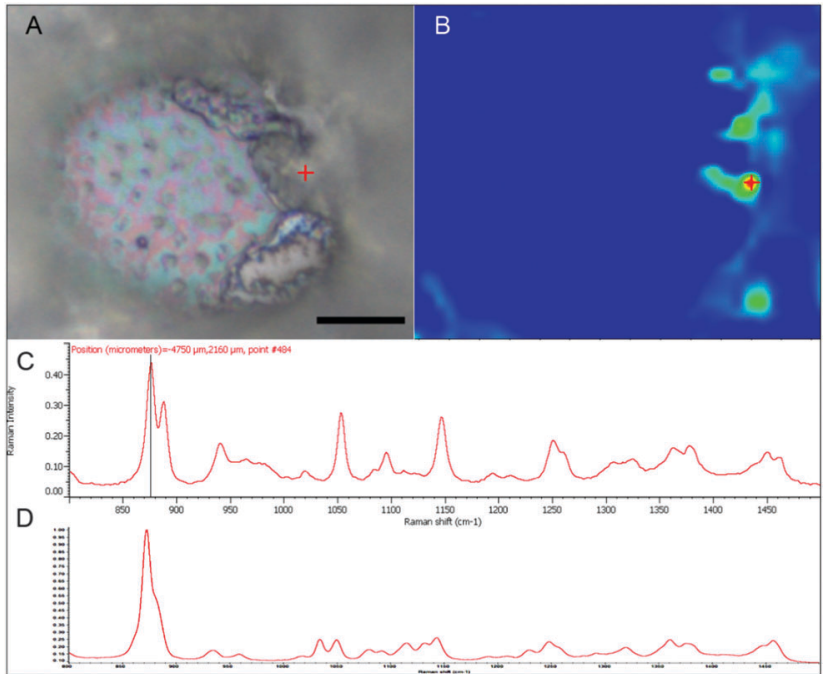

Fig. 7 Macrocystis sieve cell. (A) Brightfield micrograph. (B) Heat map of the $875 \mathrm{~cm}^{-1}$ Raman shift. (C) Raman spectrum of the point indicated by the red crosshairs in (A) and (B). (D) Raman spectrum of pure mannitol standard. Scalebar, $15 \mu \mathrm{m}$.

While the above methods provide information about the nature and localization of boron binding sites in algal cells they do not actually report localization of boron itself. To accomplish the latter we utilized energy-dispersive X-ray spectroscopy (EDS) in scanning transmission electron microscopy (STEM) mode which allowed the mapping of boron in uncoated algal sections. Uncoated thin sections $(<60 \mathrm{~nm})$ facilitated transmission of a low energy $(<7 \mathrm{keV})$ electron beam through the section, thus providing an adequate $\mathrm{K}_{\alpha} \mathrm{X}$-ray signal for mapping boron while minimizing self-absorption by the sample. The boron binding sites on or in plastids, as suggested by B-FITC, are confirmed for Ectocarpus (Fig. 8). Additional boron appears concentrated to the cell wall, a cellular component that did not exhibit B-FITC fluorescence. Macrocystis blade meristoderm cells contain significant levels of boron (see Fig. S3, ESI $\dagger$ ) while most other cell types in the blade and stipe contain a detectable amount of boron extracellularly (apoplastic) but not intracellularly (Fig. 9). An exception is the sieve cells located in the medulla (Fig. 9F) where intracellular boron is evident.

\section{Nature of the bound boron}

The chemical nature of the bound boron in intact brown algal cells was examined by ${ }^{11} \mathrm{~B}$ NMR. Previous studies have established that boron is found in sufficient quantities in brown algal cells to allow determination of some aspects of its chemical nature by this technique (Chuda et al., 1997). ${ }^{18}$ The ${ }^{11} \mathrm{~B}$ NMR spectrum of Ectocarpus is shown in Fig. 10 which shows two resonances, one at 19.2 and a second at $9.5 \mathrm{ppm}$. While broad band decoupled NMR signals cannot be strictly quantitated by signal integration, it is clear that the $19.2 \mathrm{ppm}$ band is in the majority. Previous work has established that trigonal planar boro-monoesters and boric acid itself appear near 19-20 ppm, tetrahedral monoesters between 6 and 8 ppm, tetrahedral borodiesters in the 9-10 ppm range and borate itself near $0 \mathrm{ppm} .{ }^{24}$ Based on this we assign
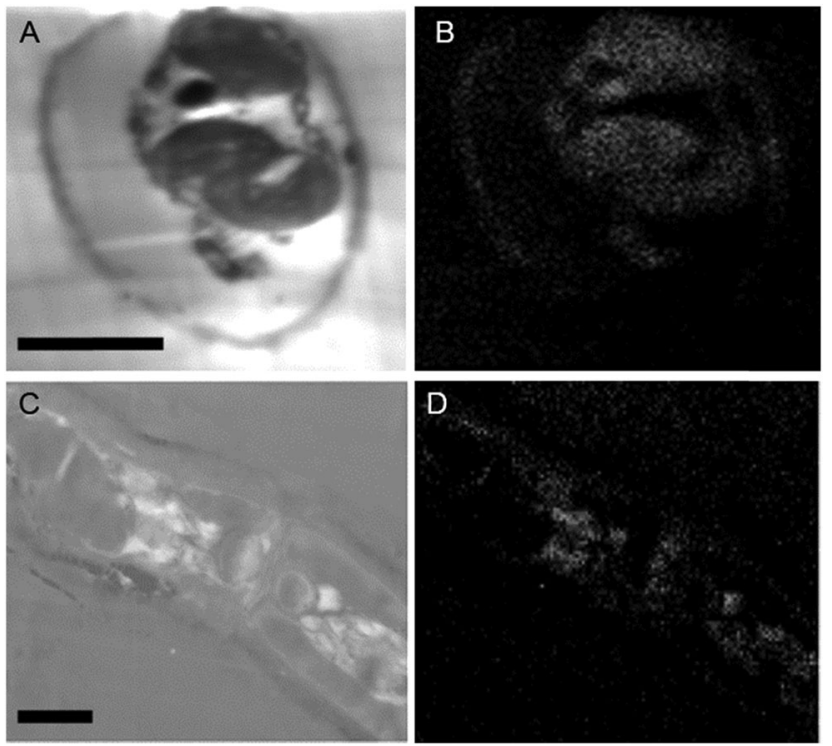

Fig. 8 Ectocarpus embedded cross-sections. Longitudinal section (A) STEM, (B) EDS. Lateral section (A) STEM. (B) EDS. Scalebars, $10 \mu \mathrm{m}$.
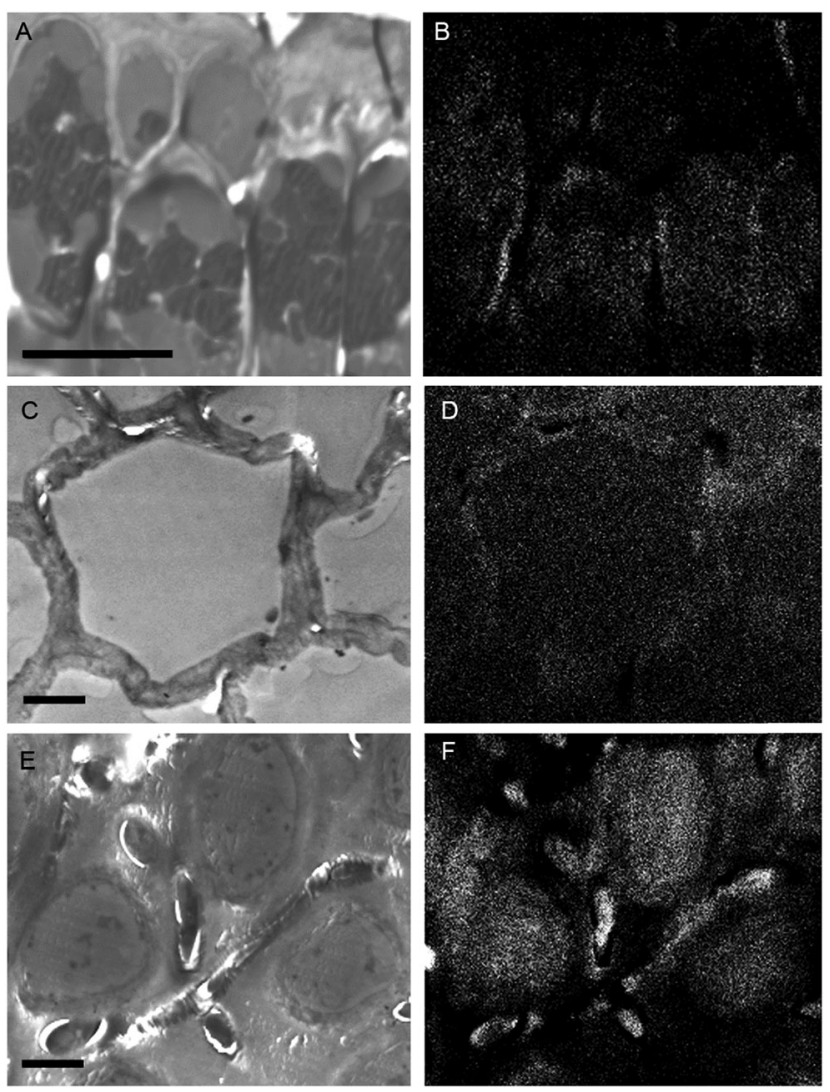

Fig. 9 Macrocystis stipe. Meristoderm (A) STEM, (B) EDS. Cortex (C) STEM, (D) EDS. Medulla (E) STEM, (F) EDS. Scalebars, $10 \mu \mathrm{m}$.

the $19.2 \mathrm{ppm}$ band in Ectocarpus as due to trigonal planar boromonoester likely from boron bound to polymeric alginate where borodiester formation is sterically restricted. The $9.5 \mathrm{ppm}$ peak is clearly that of a tetrahedral borodiester most probably 


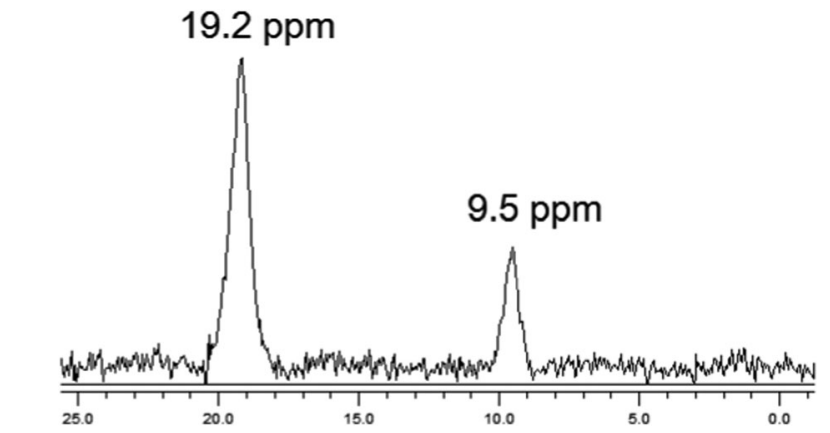

Fig. $10{ }^{11} \mathrm{~B}$ NMR of Ectocarpus.

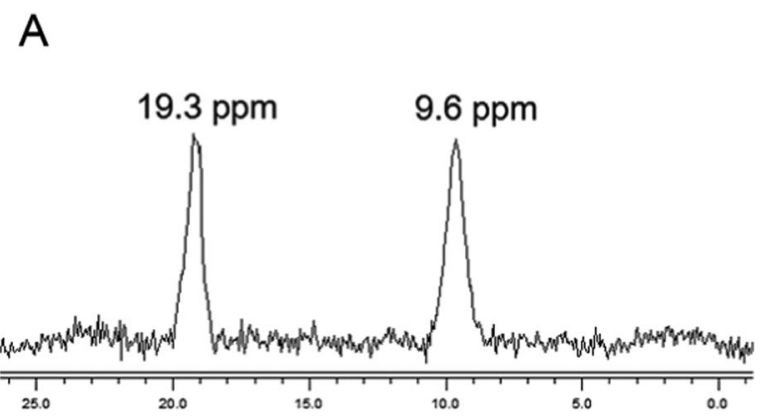

B
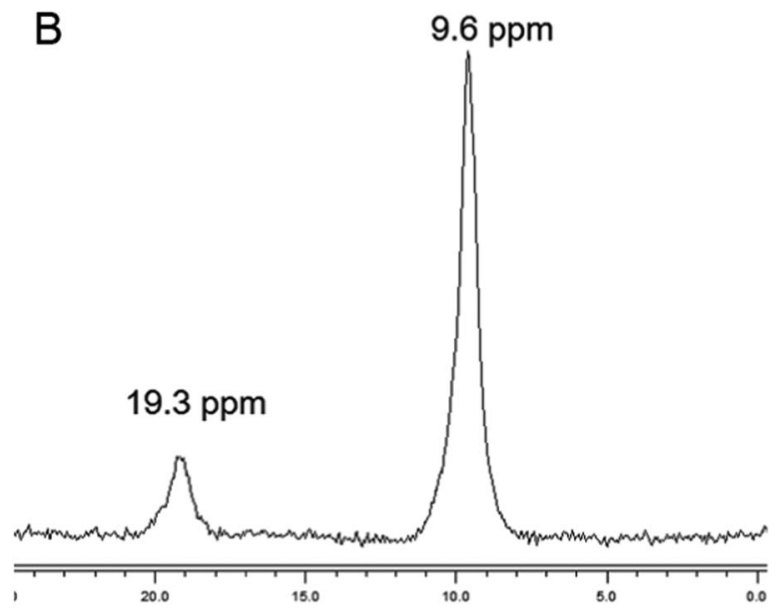

Fig. $11{ }^{11} B$ NMR of Macrocystis (A) blade (B) stipe.

the bis-mannitol complex. The ${ }^{11} \mathrm{~B}$ NMR spectra of Macrocystis blade and stipe (Fig. 11A and B, respectively) show the same two species but in different ratios. The blade seems to have a relatively small quantity of boron (based on the $\mathrm{S} / \mathrm{N}$ ratio) and roughly equivalent amount of both species being present while the stipe has both a stronger boron signal and appears to be almost entirely borodiester. This latter observation is consistent with the high concentration of mannitol found in the stipe (Reed et al., 1985). ${ }^{25}$

\section{Discussion}

A broad systematic understanding of boron uptake mechanisms is lacking for animals, though uptake is known to occur across mucous membranes of the gastrointestinal and respiratory systems. In contrast, terrestrial plants are fairly well studied with regards to boron uptake with the molecular aspects of boron transporters having recently been reviewed (Tanaka and Fujiwara, 2008). ${ }^{3}$ Boric acid is an uncharged and undissociated molecule over much of the physiological $\mathrm{pH}$ range and therefore it is this form that is considered to be the species taken up, generally assumed to occur through passive diffusion. ${ }^{26}$ However recent studies over the last decade have shown that uptake occurs as an active process mediated by active BOR transporters or facilitated by nodulin-like intrinsic proteins (NIPs). BOR1, a member of the SLC4 anion-exchanger superfamily (which also includes bicarbonate transporters), was identified as the first transport protein involved in active boron-loading of the xylem in the higher plant model Arabidopsis. ${ }^{27,28}$ Shortly afterwards, the same group found several members of the major intrinsic proteins (MIPs), namely NIP5;1, and NIP6;1 to be essential for boron uptake and plant development under boron limitation..$^{29,30}$ These molecules appear to function as channels or porins for boron. ${ }^{31}$

In contrast to the terrestrial environment, the marine environment is boron-rich, suggesting perhaps the greater need for a boron efflux system (to prevent toxicity) over one for transport. Recently, using yeast as a eukaryotic model system, several proteins in addition to BOR1 have been implicated in resistance to boron toxicity including DUR3, FPS1 and ATR1 (Kaya et al., 2009). ${ }^{32}$ It was subsequently shown that ATR1 was the primary efflux system responsible for boron tolerance in yeast and that overexpression of this protein allowed growth on media containing as much as $200 \mathrm{mM}$ boron. ${ }^{32}$ ATR1 homologs were detected in fungi, bacteria and archaea but not in the limited array of animals, vascular plants, or algae examined. Our results along with data from the literature indicate that boron is indeed taken up, likely by a facilitated diffusion mechanism and against a considerable concentration gradient. Manley reports that sieve tube sap from Macrocystis has a boron concentration between $24-32 \mathrm{mM}$ an increase over seawater concentration by a factor of 75 -fold. ${ }^{33}$ To take up boron against such a concentration gradient requires either an energy dependent transport system or an internal sink (vide infra) which removes it from equilibrium. Both mechanisms seem possible in the brown algae.

The presence of an active transport system is suggested by our concentration dependent uptake results where Ectocarpus appears to take up boron with much higher affinity but lower capacity than the system seen in either Macrocystis blade or stipe. Additionally, homologs have been identified in the Ectocarpus genome that cluster in the same clade with BOR1 of Arabidopsis, the yeast protein YNL275w (BOR1p) and the BTR1 protein of humans. ${ }^{34}$ Similar homologs are also found in the genome of the diatom Phaeodactylum tricornutum. Thus it appears that boron transporters may be widespread among marine plant-like lineages.

It is widely regarded that the primary role of boron in higher plants is the formation of cell wall carbohydrate crosslinks specifically with the peptic polysaccharide rhamnogalacturonan 
II (RGII). However, it is by no means clear it has the same role in marine brown algae whose major wall polysaccharides (alginate, fucoidan, and cellulose) are quite different. Based on our results here $\left({ }^{11} \mathrm{~B}\right.$ NMR, micro-Raman and fluorescence microscopy) and literature precedence, we would propose that in both Ectocarpus and Macrocystis some boron is indeed bound to cell wall constituents - most likely alginate - but probably does not form crosslinks. This type of interaction appears to occur mainly in the apoplast but its biological function, if any, remains unresolved. The second major sink for boron appears to be mannitol.

While much of the essentiality of boron to higher plants stems from its ability to crosslink cell wall carbohydrates, boron is thought to play a part in a number of other essential functions including transport functions, membrane and membrane-associated interactions, reproduction, and nitrogen fixation among them. Mannitol is a monomeric sugar alcohol and one of the primary photosynthetic products in brown algae. It has multiple functions, including osmoregulation, storage, and scavenging of reactive oxygen species. Having cis-1,2-diol groups and forming five membered chelate rings when ligated to boron, it forms very stable complexes with this element. Binding constants for the reactions (1) and (2)

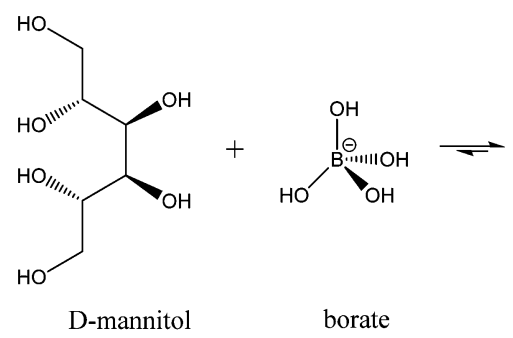

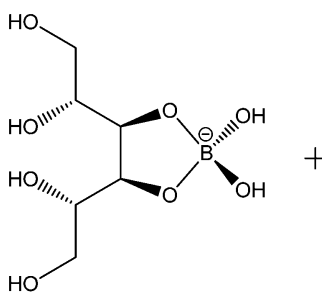

B-mannitol monoester

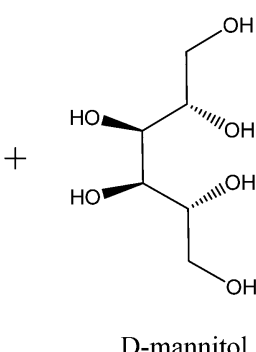

D-mannitol have been reported with $\beta_{1}=617$ and $\beta_{2}=155 .^{35}$

At the $\mathrm{pH}$ and concentrations of boron and mannitol reported by Manley in Macrocystis sieve tube sap, it is clear that essentially all the boron would be expected to be complexed as the bis-mannitol borodiester. ${ }^{36}$ This is consistent with the high level of diester seen in Macrocystis stipe as compared to blade, as the former has the higher mannitol content. It is also consistent with the generally higher level of diester in Macrocystis versus Ectocarpus as again the former has a higher reported mannitol content ( $c a .600 \mathrm{mM}$ ) compared with that of the latter (ca. $160 \mathrm{mM}) .^{25}$

As the primary photosynthetic product, mannitol accounts for the bulk of translocated metabolites in brown algae such as

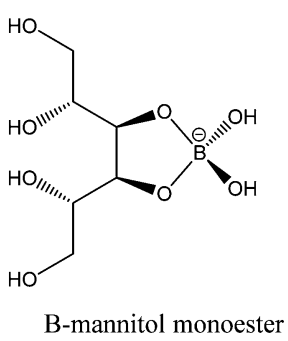

Macrocystis which, although non-vascular, displays the ability for long distance transport of nutrients. Transport velocities between $35-72 \mathrm{~cm} \mathrm{~h}^{-1}$ have been reported. ${ }^{37,38}$ The general picture that has emerged is that transport follows a source-sink model with mature blades being the source and the holdfast and the apical growing tips the sink. Using ${ }^{14} \mathrm{C}$ labeling of blades on intact plants, Schmitz and Srivastava have shown that transport of labeled carbon is toward either the apical growing areas or the holdfast depending on the position of the labeled blades and that the majority of the transported label is found in mannitol (ca. 60\%) or amino acids (ca. 30\%). ${ }^{39}$ This model is consistent with a recent transcriptomic study which indicates that photosynthesis of mannitol occurs primarily in the upper canopy while protein synthesis occurs primarily at depth near the holdfast with long distance transport of nutrients between these two sinks. ${ }^{40}$

With the majority of the data presented here it is clear that in Macrocystis that most of the boron is likely to be bound to mannitol as a diester complex. The question then is: what is the biological significance, if any, of this complexation? Is boron modulating transport of mannitol or is mannitol modulating boron transport? Alternatively, is boron modulating the role of mannitol as an osmoprotectant? These and other questions
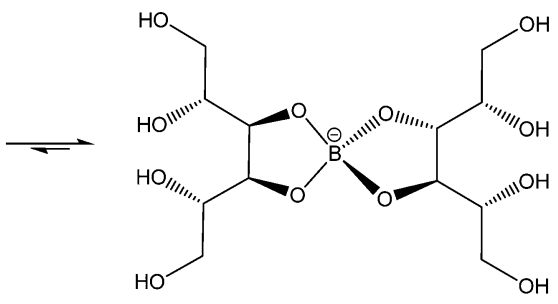

concerning the role of boron in brown algae remain under active investigation.

\section{Acknowledgements}

This research was supported by a California State University Council on Ocean Affairs, Science and Technology (COAST) Grant Development Award \#GDP-2013-002. The authors are grateful to Dr Steve Barlow and the SDSU Electron Microscope Facility for expert technical assistance and instrument time. EM has been supported by a California State University Council on Ocean Affairs, Science and Technology (COAST) graduate scholarship. 


\section{References}

1 K. Warington, The effect of boric acid and borax on the broad bean and certain other plants, Ann. Bot., 1923, 27, 629-672.

2 H. E. Goldbach, B. Rerkasem, M. A. Wimmer, P. H. Brown, M. Thellier and R. W. Bell, Boron in Plant and Animal Nutrition, Kluwer Academic/Plenum Publishers, New York, 2001.

3 M. Tanaka and T. Fujiwara, Physiological roles and transport mechanisms of boron: perspectives from plants, Pflügers Arch., 2008, 456, 671-677.

4 S. K. Yau, M. M. Nachit, J. Hamblin and J. Ryan, Phenotypic variation in boron-toxicity tolerance at seedling stage in durum wheat (Triticum durum), Euphytica, 1995, 83, 185-191.

5 M. Kobayashi, T. Matoh and J. Azuma, Two chains of rhamnogalacturonan II are cross-linked by borate-diol ester bonds in higher plant cell walls, Plant Physiol., 1996, 110, 1017-1020.

6 T. Acree, Chemistry of Sugars in Boric-Acid Solutions, Adv. Chem. Ser., 1973, (117), 208-219.

7 R. Vandenberg, J. Peters and H. Vanbekkum, The Structure and (local) Stability-Constants of Borate Esters of Monosacchharides and Disaccharides as Studied by B-11 and C-13 Nmr-Spectroscopy, Carbohydr. Res., 1994, 253, 1-12.

8 A. J. Spivack, C.-F. You and H. J. Smith, Foraminiferal boron isotope ratios as a proxy for surface ocean $\mathrm{pH}$ over the past 21 Myr, Nature, 1993, 363, 149-151.

9 Handbook of Biological Data, ed. W. S. Spector, W.B. Saunders Co., Philadelphia, PA, 1956.

10 R. Henkel, Ernährungsphysiologische Untersuchungen an Meeresalgen, insbesondere an Bangia pumila, Kiel. Meeresforsch., 1952, 8, 192-211.

11 J. C. Lewin, The boron requirement of a marine diatom, Naturwissenschaften, 1965, 52, 70.

$12 \mathrm{~J}$. Lewin, Boron as a growth requirement for diatoms, J. Phycol., 1966, 2, 160-163.

13 J. C. Lewin, Physiological studies of the boron requirement of the diatom, Cylindrotheca fusiformis Reimann and Lewin, J. Exp. Bot., 1966, 17, 473-479.

14 J. Lewin and C. Chen, Effects of boron deficiency on the chemical composition of a marie diatom, J. Exp. Bot., 1976, 27, 916-921.

15 J. McLachlan, Effects of Nutrients on Growth and Development of Embryos of Fucus-Edentatus-Pyl (Phaeophyceae, Fucales), Phycologia, 1977, 16, 329-338.

16 T. Motomura and Y. Sakai, Phycologia, 1984, 23, 331-343.

17 A. Haug, The influence of borate and calcium on the gel formation of a sulfated polysaccharide from Ulva lactuca, Acta Chem. Scand., Ser. B, 1976, 30, 562-566.

18 Y. Chuda, M. Ohnishi-Kameyama and T. Nagata, Identification of the forms of boron in seaweed by ${ }^{11} \mathrm{~B} \mathrm{NMR}$, Phytochemistry, 1997, 46, 209-213.

19 D. J. McHugh, Production, properties and uses of alginates, in Production and Utilization of Products from Commercial Seaweeds, ed. D. J. McHugh, FAO, 1987, pp. 58-115.
20 Algal culturing techniques, ed. R. A. Andersen, Academic Press, NY, 2005, ISBN: 978-0-112-088426-1.

21 K.-H. Glüsenkamp, H. Kosegarten, K. Mengel, F. Grolig, A. Esch and H. E. Goldbach, A fluorescein boronic acid conjugate as a marker for borate binding sites in the apoplast of growing roots of Zea mays L. and Helianthus annuus L, in Boron in Soils and Plants [Internet], ed. R. W. Bell and B. Rerkasem, Springer, Netherlands, 1997, pp. 229-235, available from: http://link.springer.com/chap ter/10.1007/978-94-011-5564-9_44.

22 D. Neame and G. Richards, Elementary Kinetics of Membrane Carrier Transport, 1972.

23 T. Schmid, A. Messmer, B.-S. Yeo, W. Zhang and R. Zenobi, Towards chemical analysis of nanostructures in biofilms II: tip-enhanced Raman spectroscopy of alginates, Anal. Bioanal. Chem., 2008, 391(5), 1907-1916.

24 M. Bishop, N. Shahid, J. Z. Yang and A. R. Barron, Determination of the mode and efficacy of the cross-linking of guar by borate using MAS B-11 NMR of borate cross-linked guar in combination with solution B-11 NMR of model systems, Dalton Trans., 2004, 2621-2634.

25 R. H. Reed, I. R. Davison, J. A. Chudek and R. Foster, The osmotic role of mannitol in the Phaeophyta: an appraisal, Phycologia, 1985, 24(1), 35-47.

$26 \mathrm{~J}$. A. Raven, Short- and long-distance transport of boric acid in plants, New Phytol., 1980, 84, 231-249.

27 W. B. Frommer and N. von Wiren, Plant biology - Ping-pong with boron, Nature, 2002, 420(6913), 282-283.

28 J. Takano, K. Noguchi, M. Yasumori, M. Kobayashi, Z. Gajdos and K. Miwa, et al., Arabidopsis boron transporter for xylem loading, Nature, 2002, 420, 337-340.

29 J. Takano, M. Wada, U. Ludewig, G. Schaaf, N. von Wiren and T. Fujiwara, The Arabidopsis major intrinsic protein NIP5; 1 is essential for efficient boron uptake and plant development under boron limitation, Plant Cell, 2006, 18, 1498-1509.

30 M. Tanaka, I. S. Wallace, J. Takano, D. M. Roberts and T. Fujiwara, NIP6;1 Is a Boric Acid Channel for Preferential Transport of Boron to Growing Shoot Tissues in Arabidopsis, Plant Cell, 2008, 20(10), 2860-2875.

31 Y. Kato, K. Miwa, J. Takano, M. Wada and T. Fujiwara, Highly Boron Deficiency-Tolerant Plants Generated by Enhanced Expression of NIP5;1, a Boric Acid Channel, Plant Cell Physiol., 2009, 50(1), 58-66.

32 A. Kaya, H. C. Karakaya, D. E. Fomenko, V. N. Gladyshev and A. Koc, Identification of a Novel System for Boron Transport: Atr1 Is a Main Boron Exporter in Yeast, Mol. Cell. Biol., 2009, 29(13), 3665-3674.

33 S. L. Manley, Composition of Sieve Tube Sap from Macrocystis Pyrifera (phaeophyta) with Emphasis on the Inorganic Constituents1, J. Phycol., 1983, 19(1), 118-121.

34 C. J. Carrano, S. Schellenberg, S. A. Amin, D. H. Green and F. C. Küpper, Boron and Marine Life: A New Look at an Enigmatic Bioelement, Mar. Biotechnol., 2009, 11, 431-440.

35 J. Knoeck and J. Taylor, Aqueous Boric Acid-Borate-Mannitol Equilibria, Anal. Chem., 1969, 41(13), 1730. 
36 S. L. Manley, Micronutrient uptake and translocation by Macrocystis pyrifera (Phaeophyta), J. Phycol., 1984, 20, 192-201.

37 B. Parker, Translocation in Giant Kelp Macrocystis. i. Rates Direction Quantity of C14-Labeled Products and Fluorescein, J. Phycol., 1965, 1(2), 41.

38 K. Schmitz and C. Lobban, Survey of Translocation in Laminariales (phaeophyceae), Mar. Biol., 1976, 36(3), 207-216.
39 K. Schmitz and L. Srivastava, Long-Distance Transport in Macrocystis-Integrifolia. 1. Translocation of C-14-Labeled Assimilates, Plant Physiol., 1979, 63(6), 995-1002.

40 T. Konotchick, C. L. Dupont, R. E. Valas, J. H. Badger and A. E. Allen, Transcriptomic analysis of metabolic function in the giant kelp, Macrocystis pyrifera, across depth and season, New Phytol., 2013, 198, 398-407. 